\title{
Crosstalk between the Notch signaling pathway and non-coding RNAs in gastrointestinal cancers (Review)
}

\author{
YANGYANG PAN $^{1}$, YUYAN MAO ${ }^{2}$, RONG JIN ${ }^{1}$ and LEI JIANG ${ }^{2}$ \\ ${ }^{1}$ Department of Gastroenterology; ${ }^{2}$ Central Laboratory, The First Affiliated Hospital of \\ Wenzhou Medical University, Wenzhou, Zhejiang 325000, P.R. China
}

Received August 16, 2016; Accepted September 7, 2017

DOI: 10.3892/ol.2017.7294

\begin{abstract}
The Notch signaling pathway is one of the main signaling pathways that mediates direct contact between cells, and is essential for normal development. It regulates various cellular processes, including cell proliferation, apoptosis, migration, invasion, angiogenesis and metastasis. It additionally serves an important function in tumor progression. Non-coding RNAs mainly include small microRNAs, long non-coding RNAs and circular RNAs. At present, a large body of literature supports the biological significance of non-coding RNAs in tumor progression. It is also becoming increasingly evident that cross-talk exists between Notch signaling and non-coding RNAs. The present review summarizes the current knowledge of Notch-mediated gastrointestinal cancer cell processes, and the effect of the crosstalk between the three major types of non-coding RNAs and the Notch signaling pathway on the fate of gastrointestinal cancer cells.
\end{abstract}

\section{Contents}

1. Introduction

2. The Notch signaling pathway

3. Crosstalk between the Notch signaling pathway and ncRNAs in gastrointestinal cancers

4. Conclusion

Correspondence to: Dr Lei Jiang, Central Laboratory, The First Affiliated Hospital of Wenzhou Medical University, 1 South Baixiang Street, Wenzhou, Zhejiang 325000, P.R. China

E-mail: jiangleistone79@163.com

Professor Rong Jin, Department of Gastroenterology, The First Affiliated Hospital of Wenzhou Medical University, 1 South Baixiang Street, Wenzhou, Zhejiang 325000, P.R. China

E-mail: jinrongjrjr@163.com

Key words: Notch, microRNAs, long non-coding RNAs, circular RNAs, gastrointestinal cancer

\section{Introduction}

Notch signaling is a highly conserved cell signaling pathway that is involved in multiple aspects of metazoan growth and development, including cell proliferation, differentiation and apoptosis (1). It has been suggested to be one of the most commonly activated signaling pathways in neoplastic diseases, most notably in gastrointestinal malignancies including stomach, colorectal and esophageal cancer, as well as liver and pancreatic cancers (1-3). Furthermore, the abnormal activation of Notch signaling may result from the mutation or amplification of Notch signaling components (1). As Notch signaling may regulate a plethora of genes, the dysregulation of Notch signaling often promotes tumor formation (4).

Noncoding RNAs (ncRNAs) include microRNAs (miRNAs), long noncoding RNAs (lncRNAs), circular RNAs (circRNAs), transfer RNAs, ribosomal RNAs and small nucleolar RNAs. These nucleic acids affect every stage of gene expression, from transcription and mRNA stability to mRNA translation $(5,6)$. At present, research has uncovered the critical function of ncRNAs in cancer pathogenesis (7). The dysregulated expression and dysfunction of specific ncRNAs has been demonstrated to drive the process of tumorigenesis in human cells. Three forms of ncRNAs that are particularly important for the regulation of gene expression in cells are miRNA, IncRNA and circRNA (8). An increasing number of studies have demonstrated that specific ncRNAs may interact with the Notch signaling pathway and serve important functions in tumor progression (9-12). Therefore, in the present review, the functional association between ncRNAs and the Notch signaling pathway is described.

\section{The Notch signaling pathway}

The Notch signaling pathway is composed of Notch receptors, Notch ligands, intracellular effector molecules, DNA-binding proteins and regulatory molecules. At present, four different Notch receptors have been identified in mammalian cells, which are Notch1-4. Notch receptors are single transmembrane proteins consisting of extracellular, transmembrane and intracellular domains (13). Previous studies have refined our understanding of Notch ligands. In addition to the commonly known Jagged (JAG) 1-2 and delta like canonical Notch ligand (DLL), other Notch ligands have been identified 
including delta like non-canonical Notch ligand (DLK)-1 and DLK-2/epidermal growth factor-like protein 9 (14). Notch receptors and a majority of Notch ligands have also been revealed to be type I transmembrane proteins (14). In canonical Notch signaling, Notch1-4 activate the same basic signaling pathway through the use of CBF-1, suppressor of hairless, lag-1 (CSL) transcription factors $(15,16)$. The Notch signaling pathway is activated when a Notch ligand interacts extracellularly with its specific Notch receptor between two neighboring cells (10). Upon activation, the Notch receptor is proteolytically cleaved by unidentified $\gamma$-secretase-like protease activity, which is dependent on presenilin proteins, and releases the Notch intracellular domain (NICD) $(10,16)$. NICD then translocates into the nucleus and interacts with recombination signal binding protein for immunoglobulin $\mathrm{KJ}$ region (CBF-1/RBPJ $)$, one of the mammalian CSL transcription factors. Then, with the mastermind protein, it forms a ternary complex with CSL proteins $(\mathrm{CBF}-1 / \mathrm{RBPJ} \kappa, \mathrm{Su}(\mathrm{H})$, Lag-1) that binds Notch target genes in order to promote their transcription (Fig. 1) $(10,14,15,17,18)$.

Since Notch signaling regulates the expression of multitudinous genes and modulates cell growth and metabolism, the alteration of Notch signaling activity or the deregulated expression of Notch receptors and ligands may disrupt cell physiology, thus promoting numerous disorders, including tumor malignancies (19-21). Based on its influence on various downstream functions, Notch signaling may serve oncogenic and anti-tumor functions in different types of human cancer, depending on the cellular context (22-24). In specific types of tumor or tumor stages, aberrant Notch signaling is involved in cancer recurrence, metastasis, epithelial to mesenchymal transition (EMT) and resistance to treatment (4,25-28).

\section{Crosstalk between the Notch signaling pathway and ncRNAs in gastrointestinal cancers}

The Notch signaling pathway and miRNAs. miRNAs are small ncRNAs $\sim 22$ nucleotides in length with important functions that include development, cell differentiation, regulation of the cell cycle and apoptosis of cells (29). They regulate gene expression by inhibiting translation or degrading mRNA transcripts (8). With further research, additional novel miRNAs have been demonstrated to function as oncogenes or tumor-suppressor genes in cancer, including gastrointestinal cancer. miRNA expression is frequently deregulated in cancer via a variety of mechanisms including amplification, deletion, mutation and epigenetic silencing (29). Furthermore, miRNAs are stable and present in various biofluids, and the level of miRNAs in body fluids reflect specific pathological states (30). These characteristics make them novel and effective biomarkers for human cancer diagnosis. It has been well documented that the Notch signaling pathway is one of the most important pathways in the regulation of the carcinogenesis and progression of gastrointestinal cancer. It may function alone, or in crosstalk with other pathways and regulatory factors that serve critical functions in tumor development. There is a notable association between miRNAs and the Notch signaling pathway, and several miRNAs both regulate and are regulated by the Notch pathway (13). In the present study, a number of typical miRNAs that interact with

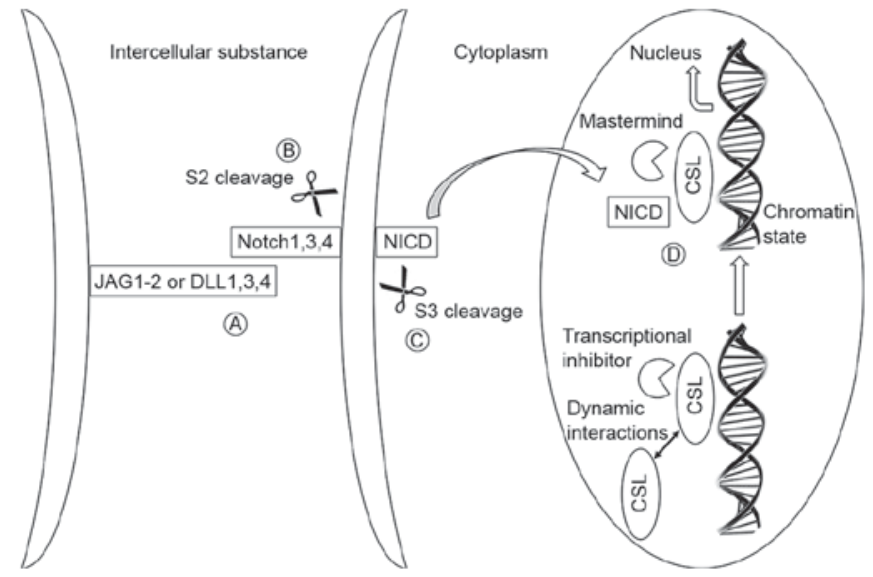

Figure 1. Functional mechanism of the Notch signaling pathway. (A) The Notch extracellular domain comes into contact with Notch ligands including JAG1,2 and DLL1, 3 and 4; (B) The NICD is then released via disintegrin- and metalloproteinase-dependent cleavage at the S2 site at the extracellular position of the membrane-spanning domain; (C) Intramembranous $\gamma$-secretase-dependent cleavage then occurs at the S3 site to transport NICD into the nucleus. (D) In the nucleus, NICD interacts with cell-specific factors CSL and Mastermind to form a ternary complex and bind Notch target genes to promote their transcription. JAG1, Jagged1; JAG2, Jagged2; DLL, delta like canonical Notch ligand; NICD, Notch intracellular domain; CSL, CBF-1, suppressor of hairless, lag 1.

Notch signaling and their functions in gastrointestinal cancer are highlighted (Table I).

Esophageal cancer. Esophageal cancer is one of the ten most common malignant tumors with the highest incidence in 2012 globally, and is more common in less developed areas than developed areas (31). The two main types of esophageal cancer are esophageal squamous cell carcinoma (ESCC) and adenocarcinoma (31). Notch1 is one of the well-known ESCC-associated genes (32). Deviant activation of Notch signaling has been identified as associated with the initiation and evolution of esophageal cancer, and a number of miRNAs are linked with this pathway (33).

The expression level of miR-29a has been demonstrated to be markedly downregulated in ESCC tissue and the ESCC TE-1 cell line when compared with matched normal esophageal tissue and cells. In addition, induced expression of miR-29a significantly prevented cell growth and migration in the TE-1 cell line (34). Furthermore, the aforementioned study identified that the exogenous expression of miR-29a repressed ESCC cell proliferation by downregulating nuclear factor I A (NFIA) and upregulating the Hes family BHLH transcription factor 1 (Hes1). Target Scan prediction identified a potential binding site for miR-29a at the position 240-246 of the NFIA 3' untranslated region (UTR) mRNA, and identified that the knockdown of NFIA may increase Hes1 expression and inhibit the growth of TE-1 cells (34). Since Hes1 is one of the key effectors of the Notch signaling pathway, miR-29a may indirectly activate the Notch pathway, although it has no effect on the expression of Notch1 (34).

The miR-200 family is downregulated in numerous types of cancer, including ESCC. It negatively regulates the zinc finger E-box binding homeobox (ZEB), a cluster of transcription factors indispensable in cancer stem cell function and 
Table I. miRNAs are associated with the Notch signaling pathway in gastrointestinal cancers.

\begin{tabular}{|c|c|c|c|c|c|}
\hline Author, year & Names & Expression $^{\mathrm{a}}$ & Targets & Biological events & (Refs.) \\
\hline Liu et al, 2015 & $\operatorname{miR}-29 a$ & $\downarrow$ & Hes 1 & Esophageal cancer & (34) \\
\hline Furukawa et al, 2013 & miR-1 & $\downarrow$ & Notch3 & Colorectal cancer & (46) \\
\hline Xiong et al, 2014 & $\operatorname{miR}-21$ & $\uparrow$ & Notch1 & Colorectal cancer & (47) \\
\hline $\begin{array}{l}\text { Bu et al, 2013; Ji et al, 2008; } \\
\text { Roy et al, 2012; Ji et al, 2009; } \\
\text { Cifarelli et al, } 2015\end{array}$ & miR-34a & $\uparrow \downarrow^{\mathrm{b}}$ & Notch1 & $\begin{array}{l}\text { Gastric cancer/colorectal } \\
\text { cancer/pancreatic cancer }\end{array}$ & $(9,38,48,72,73)$ \\
\hline Yang et al, 2015 & $\operatorname{miR}-100$ & $\uparrow$ & HS3ST2 & Gastric cancer & (37) \\
\hline Jiang et al, 2016 & $\operatorname{miR}-124$ & $\downarrow$ & JAG1 & Gastric cancer & $(40)$ \\
\hline $\begin{array}{l}\text { Sureban et al, 2011; } \\
\text { Sureban et al, } 2011\end{array}$ & miR-144 & $\downarrow$ & Notch1 & $\begin{array}{l}\text { Colorectal cancer/ } \\
\text { pancreatic cancer }\end{array}$ & $(51,74)$ \\
\hline Jung et al, 2016 & miR-148a & $\downarrow$ & Notch1 & Liver cancer & $(58)$ \\
\hline Hashimoto et al, 2010 & miR-181 & $\downarrow$ & Notch4 & Gastric cancer & $(42)$ \\
\hline $\begin{array}{l}\text { Ohashi et al, 2011; } \\
\text { Bao et al, 2011; } \\
\text { Brabletz et al, } 2011\end{array}$ & $\mathrm{miR}-200 \mathrm{~b} / \mathrm{c}$ & $\downarrow$ & Notch3/Notch1 & $\begin{array}{l}\text { Esophageal cancer/ } \\
\text { pancreatic cancer }\end{array}$ & $(35,68,76)$ \\
\hline $\begin{array}{l}\text { Wang et al, 2015; } \\
\text { Liu et al, } 2014\end{array}$ & miR-206 & $\downarrow$ & Notch3 & $\begin{array}{l}\text { Colorectal cancer/ } \\
\text { liver cancer }\end{array}$ & $(56,63)$ \\
\hline Giovannini et al, 2014 & $\operatorname{miR}-221$ & $\downarrow$ & Notch3 & Liver cancer & $(65)$ \\
\hline Ma et al, 2015 & $\operatorname{miR}-223$ & $\uparrow$ & Notch1 & Pancreatic cancer & (78) \\
\hline Zhang et al, 2014 & $\operatorname{miR}-224$ & $\downarrow$ & JAG1 & Pancreatic cancer & (81) \\
\hline Yan et al, 2016 & $\operatorname{miR}-935$ & $\downarrow$ & Notch1 & Gastric cancer & (43) \\
\hline
\end{tabular}

${ }^{a}$ Representing the expression of miRNAs in specific types of cancer. ${ }^{b}$ miR-34a is upregulated in esophageal cancer while downregulated in the other gastrointestinal cancers. miRNA/miR, microRNA; Hes1, Hes family BHLH transcription factor 1; HS3ST2, heparan sulfate-glucosamine 3-sulfotransferase 2; JAG1, Jagged1.

EMT (35). Previous research has revealed that the inhibition of Notch3 leads to a downregulation of the miR-200 family and promotes EMT via the upregulation of ZEBs in ESCC (35). Additionally, transforming growth factor (TGF)- $\beta$ induces ZEB1 and ZEB2 to increase the production of EMT markers in Notch3 knockdown ESCC cells, thus demonstrating that the inhibition of Notch 3 promotes TGF- $\beta$-mediated EMT via the upregulation of ZEBs as a result of the decreased level of miR-200 family members in ESCC (35).

Gastric cancer. Although there is an overall downward trend of morbidity, gastric cancer remains a high-incidence neoplastic disease, particularly in eastern Asia (31). Previous studies have identified that the Notch signaling pathway serves oncogenic and tumor suppressor functions in gastric cancer $(36,37)$. A number of miRNAs are regarded as oncogenic genes, whilst others are thought to possess tumor-suppressor capacities. Several miRNAs have been considered to possess a regulatory effect on Notch signaling, or be regulated by Notch signaling in gastric cancer.

One such miRNA that serves a tumor-suppressor function is miR-34. The miR-34 family consists of miR-34a, b and c (38). It has been demonstrated to regulate various types of digestive system tumors, including pancreatic, colorectal and gastric cancer (Table I). Notch is one of the targets of
miR-34, which has an oncogenic effect on gastric cancer cells (39). Notch1 is inhibited by miR-34a, b, c, while Notch2 and 4 are inhibited by miR-34b, and Notch1-4 are all inhibited by miR-34c (38). miR-34 partially restores tumor protein P53 (p53) tumor-suppressing functions, including inhibiting cell growth and inducing apoptosis, which leads to the chemosensitization of p53-deficient gastric cancer cells (38). Furthermore, miR-34 inhibits cancer stem cell self-renewal partially through the modulation of the following downstream targets: B-cell lymphoma protein 1 , Notch and high mobility group AT-hook 2 (38).

Another cancer-associated miRNA is miR-100, which was identified as an oncogene that was significantly upregulated in human epithelium-derived gastric cancer cells in a previous study (37). Silencing of miR-100 may activate Notch through an increase in the expression level of heparan sulfate-glucosamine 3-sulfotransferase 2 (HS3ST2), a target gene of miR-100 (37). miR-100 antagonism has also been demonstrated to sensitize cancer cells to chemotherapy in gastric epithelial tumor cells (37). The results of this previous study suggest that the antagonism of miR-100 may increase apoptosis in epithelium-derived gastric cancer cells via the upregulation of HS3ST2, subsequently activating the Notch signaling pathway (37). The dual function of the Notch signaling pathway in cancer genesis and development is 
present in many types of cancer, however further research is required to identify the reason for these opposing effects in gastric cancer.

miR-124 is an important miRNA affecting gastric cancer progress. A previous study has revealed that miR-124 is downregulated in gastric cancer, and that the ectopic expression of miR-124 suppresses cell growth, migration and invasion, and induces cell cycle arrest in gastric cancer cells (40). miR-124 may negatively regulate Notch1 signaling by targeting the Notch ligand JAG1, whilst the activation of Notch1 signaling via the overexpression of Notch intracellular domain (NICD) led to the repression of miR-124 expression, suggesting the existence of a regulatory feedback loop between miR-124 and the Notch1 signaling pathway in gastric cancer cells (40). miR-124-3p was also demonstrated to be significantly downregulated in gastric cancer tissues compared with adjacent normal gastric tissues, and the mir-124-3p low-expression group demonstrated increased lymph node metastasis and lymphatic invasion than the high-expression group (41).

miR-181c has been revealed to be downregulated in gastric cancer tissues due to the methylation status in $\mathrm{CpG}$ islands in a region from -1297 to -987 upstream (42). A previous study demonstrated that the overexpression of miR-181c inactivated several tumorigenesis-associated pathways, including the Notch and $\delta$-Notch signaling pathways (42). Furthermore, the aforementioned study demonstrated that there is a significant reduction of gastric cancer cell proliferation in pre-miR-181c-transfected cells, and that Notch2 and Notch4 are down-regulated by miR-181c. However, a luciferase assay revealed that miR-181c has a binding site at the Notch4 3'UTR but not at the Notch2 3'UTR, indicating that Notch4 may be a more likely target of miR-181c than Notch2 (42). The results of this previous study indicated that the inhibitory effect on cell proliferation, mediated by miR-181c may act partially through Notch4, one of its targets (42).

miR-935 has been revealed to serve a tumor suppressor function in gastric signet ring cell carcinoma (GSRCC), a unique pathological type of gastric carcinoma with high invasiveness and poor prognosis. Notably, the expression of miR-935 has been demonstrated to be lower in gastric cancer tissues compared with paired normal tissues, and is markedly lower in GSRCC than in non-GSRCC (43). miR-935 was revealed to suppress Notch1 expression by directly targeting the Notch1 mRNA 3'UTR, and there was a significant inverse correlation between miR-935 and Notch1 expression in gastric carcinoma (43). Furthermore, the overexpression of miR-935 negatively regulated GSRCC cell proliferation, migration and invasion, and the forced expression of NICD may rescue the tumor suppressive effects of miR-935 overexpression on GSRCC (43). This data suggests that miR-935 acts as an anti-carcinoma gene by inactivating the Notch signaling pathway in gastric cancer, particularly in GSRCC (43).

Colorectal cancer. Colorectal cancer is the second and third most frequently diagnosed cancer in 2012 globally in women and men, respectively (31). Its incidence and mortality are higher in developed areas compared with underdeveloped areas (31). Numerous cellular events are involved in the occurrence of colorectal cancer, one of which is the deregulation of miRNAs. miRNAs are known to be associated with processes of growth and metastasis in colorectal cancer (44). In addition, previous studies have demonstrated that the Notch signaling pathway is indispensable in the self-renewal capability of tumor-initiating cells and the inhibition of the differentiation of normal colonic epithelial cells (45), thus serving a carcinogenic function in colorectal cancer development. To date, numerous miRNAs associated with the Notch signaling pathway have been uncovered, which function together to affect the fate of colorectal cancer cells.

miR-1 is downregulated in colorectal cancer tissues, and restoring the expression of miR-1 may suppress Notch3 expression by directly binding to the Notch3 mRNA 3'UTR region (46). Notch3 signaling is involved in aberrant overexpression of Rho guanine nucleotide exchange factor 4 (Asef), a guanine-nucleotide exchange factor (46). Activating the miR-1-Notch3-Asef pathway inhibits colorectal tumorigenesis, as well as the migration and invasion of colorectal tumor cells (46). In addition, of the five Notch ligands, DLL4 has been suggested to induce Notch3-Asef pathway-mediated cell migration (46).

miR-21, an onco-miRNA, is upregulated in numerous solid tumors including colorectal cancer (47). Xiong et al (47) measured Notch1 and miR-21 expression in colorectal cancer tissues and adjacent non-tumor tissues of 102 patients by reverse transcription polymerase chain reaction analysis, western blotting and immunohistochemistry. The expression levels of Notch1 and miR-21 were demonstrated to be upregulated in advanced-stage colorectal cancer and positively correlated with tumor stages. Thus, it may be theorized that crosstalk exists between Notch-1 and miR-21 in colorectal cancer development, though the mechanisms remain unclear.

miR-34 exerts a similar tumor suppressive effect on colon cancer cells, to that on gastric cancer cells. It was revealed that miR-34a and miR-34c expression were downregulated in colon cancer tissues, and that the decreased level of miR-34 in colon cancer is partially due to the hyper-methylation of the miR-34 gene promoter (48). Notch1 has been identified as a direct target of miR-34b and 34c in HeLa cells $(48,49)$. miR-34a may reduce the expression of Notch-1 in colon cancer cells (48). Notably, research has also demonstrated that miR-34a may act as a bimodal switch to regulate Notch1, to determine the cell fate of early state dividing colon cancer stem cells (CCSCs) (9). High miR-34a levels suppress Notch signaling and promote asymmetric division, whereas low miR-34a levels upregulate Notch signaling and promote the self-renewing symmetric division of CCSCs (9).

miR-144 is regarded as a tumor suppressor gene in colorectal cancer, and the silencing of miR-144 has been associated with poor prognosis in patients with colorectal cancer (50). miR-144 targets Notch1 by binding to its 3' UTR (51). In addition, doublecortin like kinase 1 (DCAMKL1), a novel putative intestinal stem cell marker, has been revealed to negatively regulate miR-144 expression in colorectal cancer cells, which in turn regulates the post-transcriptional control of Notch1. Finally, the inhibition of DCAMKL1 or Notch is capable of arresting tumor growth in colorectal cancer (51).

miR-206 is downregulated in numerous types of human malignancies, including several gastrointestinal cancers, for example colorectal (52) and gastric cancer (53). Previous studies have demonstrated that Notch3 is a target of miR-206 
in myoblasts and HeLa cells $(54,55)$. Another previous study has revealed that the interaction between miR-206 and Notch3 also occurs in colorectal cancer cells (56). It was reported that miR-206 inhibited cancer cell proliferation and migration, and induced apoptosis though numerous pathways, including the Notch signaling pathway (56). The aforementioned study additionally demonstrated that miR-206 is linked with Notch-associated molecules, including JAG1 and Hes related family BHLH transcription factor with YRPW motif 1 (56). The results of this previous study suggest that miR-206 serves a tumor suppressor function in colorectal cancer cells partially via the negative control of the Notch signaling pathway.

Liver cancer. Liver cancer is the second leading cause of cancer mortality in men in 2012 worldwide (31). The rates of liver cancer mortality are highest in the east and south-east of Asia as well as in northern and western Africa, whilst China alone accounts for $\sim 50 \%$ of the total number of cases and mortalities (31). The Notch-signaling pathway is becoming increasingly recognized to be involved in liver physiological metabolism and biological functions including liver regeneration and repair, inflammation, and carcinogenesis $(3,57)$. Furthermore, miRNAs have been recognized to have close contact with Notch signaling and to exert a substantial biological effect on the progression of hepatocellular carcinoma (HCC). The interplay between differing miRNAs and the Notch signaling pathway is elaborated on below.

miR-148a is downregulated in HCC, and the restoration of miR-148a expression levels may reduce liver fibrosis and inhibit tumor growth (58). Conserved helix-loop-helix ubiquitous kinase (IKKa) is a direct target of miR-148a, which binds to the 3'UTR site of IKKa mRNA. It has been reported that IKK $\alpha$ may mediate Notch signaling activation through regulation of NUMB, Endocytic Adaptor Protein (NUMB), as NUMB may inhibit Notch signaling in HCC (59-61). The silencing of IKKa may induce hepatocytic differentiation, a similar effect to the upregulation of miR-148, whilst the overexpression of Notch 2 may reverse this phenomenon (58). The results of this previous study suggest that miR-148a is a novel negative regulator of the IKK $\alpha / \mathrm{NUMB} / \mathrm{Notch}$ signaling pathway that directly targets IKK $\alpha$ expression (58), and that miR-148a may be a potential target for molecular therapy and allow the prevention of HCC.

miR-206 is known to regulate cell proliferation and migration and is involved in numerous malignancies, and its tumor suppressor function in colorectal cancer has been elaborated above. Previous studies have demonstrated that miR-206 has a similar effect in HCC (62). Notch3 has been demonstrated to be significantly upregulated in the cytoplasm of HCC samples. Additionally, Notch3 and one of its targets, Hes1, were downregulated in miR-206 overexpressing HepG2 cells (63). This previous study also revealed that miR-206 overexpression promotes apoptotic cell death, induces cell cycle arrest and impairs cellular migration in HepG2 cells (63). Taken together, the results of the aforementioned study indicate that the effects of miR-206 on HCC cells are potentially partially dependent on the Notch3 signaling pathway (63). Nevertheless, the specific underlying mechanisms of this action remain unclear.

miR-221, a tumor suppressor gene may be indirectly regulated by the Notch signaling pathway. Previous studies have demonstrated that Notch3 controls miR-221 expression through Hes1, one of the primary targets of Notch signaling (64), and it was later demonstrated that it may bind to the miR-221 gene promoter (65). Furthermore, miR-221 has been revealed to be significantly decreased in HCC, and the restoration of miR-221 resulted in the increase of the expression level of p53, a well-known tumor suppressor gene, through the repression of mouse double minute protein 2 (MDM2) (66). The silencing of Notch3 is strengthened by the effect of MDM2 inhibitors (65). Therefore, the suppression of p53 by Notch 3 is controlled partially by the feed-forward circuit involving p53, miR-221 and MDM2 (65).

Pancreatic cancer. Pancreatic cancer is the leading cause of cancer associated mortality worldwide in 2012 (31). In previous years there has been a trend of growing rates of morbidity, particularly in less developed areas $(31,67)$. The one factor responsible for the poor prognosis of this disease is the absence of specific symptoms to allow for early detection $(68,69)$. It has been noted that Notch signaling is required for pancreatic ductal adenocarcinoma (PDAC) progression (70). One previous study revealed that Notch signaling serves an oncogenic function at an early stage, and serves a tumor suppressive function at an advanced stage in pancreatic intraepithelial neoplasia pancreatic cancer, one of the precursor lesions of PDAC (71). This previous study also suggested that a number of miRNAs are associated with Notch signaling and may have a major impact on the occurrence and development of pancreatic cancer. Elucidating the underlying mechanism of disease is necessary in order to further our understanding of this malignancy.

The miR-34 family, a well-known tumor suppressor miRNA family, has functions in other gastrointestinal cancers that were elaborated on earlier in this review. Previously, the interaction between miR-34 and Notch signaling has been confirmed to also exist in pancreatic cancer. The miR-34 family has differing effects on Notch signaling members, as miR-34a, b and c negatively control the expression of Notch1 and Notch2, but have a limited effect on Notch3 in the pancreatic cancer cell line MiaPaCa2 (72). In addition, the overexpression of miR-34a by metformin and rapamycin was demonstrated to inactivate the Notch signaling pathway by directly binding to Notch, which resulted in the prevention of pancreatic cancer growth in obese pre-diabetic mice (73).

The function of miR-144 in pancreatic cancer is similar when compared with colorectal cancer. It has been demonstrated that miR-144 may negatively regulate Notch1 expression levels by binding to the 3'UTR site in human pancreatic cells (74). Furthermore, it was also demonstrated that DCAMKL1, a microtubule-associated kinase regarded as a pancreatic stem cell marker, downregulates pre-miR-144 levels in human pancreatic cancer cells and normal mouse pancreas cells (74). The results of this previous study suggest that DCAMKL1 may induce the activation of Notch signaling by silencing miR-144 expression, which regulates EMT in pancreatic cancer (74).

The miR-200 family is composed of miR-200a, miR-200b, miR-200c, miR-141 and miR-429. Research has identified that Notch1 is one of the target genes of the miR-200 family which includes (miR-200b, miR-200c), whilst JAG1 may be regulated by miR-200b, c and miR-141 by direct binding to 
Table II. Long noncoding RNAs and their association with the Notch signaling pathway in cancer.

\begin{tabular}{|c|c|c|c|c|c|}
\hline Author, year & Names & Expression & Targets & Biological events & (Refs.) \\
\hline Pei and Wang, 2015 & GAS5 & $\downarrow$ & Notch1 & Breast cancer & (101) \\
\hline Wang et al, 2015 & NALT & $\uparrow$ & Notch1 & $\begin{array}{l}\text { Pediatric T-cell acute } \\
\text { lymphoblastic leukemia }\end{array}$ & (11) \\
\hline Hang et al, 2015 & AK022798 & $\uparrow$ & Notch1 & Gastric cancer & (85) \\
\hline Tang et al, 2014 & Linc00974 & $\uparrow$ & & Hepatocellular carcinoma & (87) \\
\hline Trimarchi et al, 2014 & LUNAR1 & $\uparrow$ & Notch1 & T-cell acute lymphoblastic leukemia & (102) \\
\hline
\end{tabular}

GAS5, growth arrest specific 5; NALT, NOTCH1 associated lncRNA in T-cell acute lymphoblastic leukemia 1; AK022798, Homo sapiens cDNA FLJ12736 fis, clone NT2RP2000327; Linc00974, long intergenic non-protein coding RNA 974; LUNAR1, leukemia-associated non-coding IGF1R activator RNA 1 .

the JAG1 3'UTR (75,76). The inhibition of Notch signaling activity via the knockdown of JAG1 may reduce the proliferation and increase the apoptosis of the Panc1 cell line (76). The EMT activator, ZEB1, has also been revealed to activate Notch signaling by silencing miR-200 family members (miR-141 and 200c) in pancreatic cancer cells (76). In addition, miR-200b may regulate EMT partially through targeting Notch1 in pancreatic cancer cells (68).

miR-223 has been demonstrated to serve a critical function in the regulation of cell proliferation, apoptosis, migration and invasion in pancreatic cancer cells $(77,78)$. Ma et al (78) revealed that the inhibition of miR-223 may reduce cell motility and invasion, as well as reverse EMT in gemcitabine-resistant (GR) pancreatic cancer cells. Furthermore, it was identified that F-box and WD repeat domain-containing 7 (Fbw7) was markedly decreased in GR cells whilst the Fbw7 substrate Notch1 expression level was significantly increased. Silencing miR-223 may upregulate Fbw7 expression levels and downregulate Notch1 expression levels in GR pancreatic cancer cells (78). As previously mentioned, Notch signaling has the potential to mediate EMT in pancreatic cancer, and the results of this previous study suggest that the EMT-mediating effect of miR-223 on pancreatic cancer may be partially due to the activation of the Notch signaling pathway, via the downregulation of Fbw7.

miR-224 has been revealed to be upregulated in various types of tumor when functioning as an oncogene (79-81). Nevertheless, a previous study identified that miR-224 was downregulated in mucinous cystic neoplasms (MCNs) of the pancreas (81). It has been demonstrated that JAG1 expression levels are significantly upregulated in tumor tissues when compared with normal tissues, and miR-224 regulates JAG1 expression by binding JAG1 mRNA at its 3'UTR (81). Notch signaling is well-documented to be associated with various pancreatic diseases $(81,82)$, including tumorigenesis and tumor progression (81). Therefore, it may be speculated that miR-224 has the capacity to stimulate oncogenesis in MCNs through the negative control of JAG1 (81).

In addition, Notch1 has been revealed to be negatively correlated with let- $7 \mathrm{~b}$ and $\mathrm{c}$ expression, yet is positively correlated with miR-21 expression in the pancreatic cancer cell line AsPC-1. Furthermore, the overexpression of Notch1 increased the expression of miR-21, a potential oncogenic regulator, whilst decreasing the expression of miR-200b, miR-200c, let-7b and let-7c in AsPC-1 cells, suggesting that Notch1 may be involved in regulating the expression of these genes (68), although the mechanism and potential function remains unclear.

The Notch signaling pathway and lncRNAs. LncRNAs, which may be $>200$ nucleotides in size, account for the largest portion of RNA genes transcribed in cells. These transcripts seem to exert an effect on a diverse number of cellular maintenance functions including protein scaffolding, chromatin looping and the regulation of mRNA stability (8). LncRNAs are now regarded as a novel class of non-coding RNAs that contribute to cancer development and progression (83). Identical to miRNAs, different lncRNAs may serve tumor-promoting or tumor-suppressing functions in the formation and development of a tumor (84). Despite the limited number of studies demonstrating the association between IncRNA and the Notch signaling pathway, certain studies have revealed several lncRNAs that are associated with Notch signaling in gastrointestinal cancers (Table II).

The IncRNA AK022798 is upregulated in gastric cancer and serves important functions in tumorigenesis, as a previous study suggested (85). The silencing of IncRNA AK022798 by specific siRNAs not only decreases the expression of multidrug resistance-associated protein 1 (MRP1) and P-glycoprotein, but also enhances the apoptotic activity of certain cisplatin-resistant gastric cancer cell lines (including SGC7901/DDP and BGC823/DDP cell lines) (85). This previous study also suggested that Notch1 is significantly upregulated in SGC7901/DDP and BGC823/DDP cells (85). The activation of Notch1 via transfection of the Notch1 overexpression vector plasmid may promote lncRNA AK022798 expression and increase the expression of MRP1, P-glycoprotein, and reduce the apoptosis of SGC7901 and BGC823 cells (85). The results of this previous study suggest that Notch1 may promote cisplatin-resistant gastric cancer formation and inhibit apoptosis, at least partially through upregulating the expression of IncRNA AK022798 (85), whilst the regulation mechanism remains unclear.

An accumulating number of studies have demonstrated that a class of IncRNAs are dysregulated in HCC and are associated with tumorigenesis, metastasis, prognosis and diagnosis (86). 
Table III. Circular RNAs as potential biomarkers for gastrointestinal cancer.

\begin{tabular}{llcl}
\hline Author, year & \multicolumn{1}{c}{ Names } & Expression & \multicolumn{1}{c}{ Biological events } \\
\hline Li et al, 2015 & ITCH & $\downarrow$ & Esophageal cancer \\
Li et al, 2015 & hsa-circ-002059 & $\downarrow$ & Gastric cancer \\
Wang et al, 2015 & hsa-circ-001988 & $\downarrow$ & Colorectal cancer \\
Xie et al, 2016 & hsa-circ-001569 & $\uparrow$ & Colorectal cancer \\
Qin et al, 2016 & hsa-circ-0001649 & $\downarrow$ & Hepatocellular carcinoma \\
Shang et al, 2016 & hsa-circ-0005075 & $\uparrow$ & Hepatocellular carcinoma \\
\hline
\end{tabular}

ITCH, Itchy E3 ubiquitin protein ligase.

An example of such an lncRNA is Linc00974. It was demonstrated that Linc00974 was upregulated in HCC owing to an abnormal hypo-methylation in the promoter. Furthermore, Pearson correlation analysis indicated a positive correlation between Linc00974 and KRT19 expression that was later reported as a biomarker for tumor growth and metastasis in HCC (87). Knockdown of Linc00974 or keratin 19 (KRT19) by short hairpin RNA inhibited cell proliferation and migration, and induced cell apoptosis in HCC. Furthermore, KRT19 expression levels were downregulated when Linc00974 was knocked down, and this was reversed when miR-642 was absent, indicating that Linc00974 may act as a 'sponge' to absorb miR-642, which would normally suppress KRT19 (87). In addition, the same previous study also revealed a markedly reduced level of Notch1, JAG1, and deltex E3 ubiquitin ligase 1 in KRT19 knockdown Huh7 cells. (87). Based on the results of this previous study, it was proposed that Linc00974 may induce the upregulation of KRT19 via competing endogenous RNA interactions, resulting in the activation of the Notch signaling pathway (87).

The Notch signaling pathway and circRNAs. CircRNAs are a novel class of ncRNAs characterized by the presence of a covalent bond linking the 3 ' and 5 ' ends generated by back-splicing (88). They have previously demonstrated substantial capabilities as gene regulators in human cell progression, including in tumor development, and have been revealed to be abundant, conserved and stable in the cytoplasm $(89,90)$. Despite the limited recognition of the functional mechanisms of circRNAs in the progression of tumors, circRNAs may act as miRNA 'sponge'. For instance, ciRS-7 was demonstrated to bind miR-7 specifically to prevent the partial biological function of the latter, including regulating epidermal growth factor receptor signaling in tumor cells $(91,92)$. Similarly, in another circRNA sex-determining region Y (SRY), functions by controlling the expression level of miR-138 and inhibits its biological effects, mainly including the enhancement of proliferation, migration and invasion in tumor cells (92). Previously, a novel circRNA, circHIPK3, was reported to be significantly upregulated in HCC compared with corresponding normal tissues and promoted HCC cell proliferation (93). This previous study also noted that circHIPK3 served as a sponge for multiple miRNAs and may directly bind to miR-124 in order to inhibit the activity of the latter (93). miR-124, as aforementioned, possesses the capability to negatively regulate the Notch signaling pathway, thus it may be hypothesized that circHIPK3 activates the Notch signaling pathway by preventing miR-124 expression. Additionally, circ001569 has been demonstrated to be upregulated in colorectal cancer tissues, and may promote colorectal cancer cell proliferation and invasion by regulating miR-145 and its targets (94).

CircRNAs are not only associated with cancer-related miRNAs, but also regulate cancer-associated pathways (92). Since miRNAs participate in various signaling pathways to exert an effect on the fate of tumor cells, there is the potential that circRNA-miRNAs may also contribute to this function. Furthermore, circRNAs may regulate mRNA transcription and control protein production (90). In addition, several specific circRNAs possess the potential to become novel biomarkers in gastrointestinal cancers (Table III), including has-circ-002059, hsa-circ-001988, hsa-circ-0001649 and circ-0005075. Hsa-circ-002059, hsa-circ-001988 ahashsa-circ-0001649 were revealed to be significantly downregulated in gastric cancer, colorectal cancer and HCC tissues, respectively (95-98), whilst circ-0005075 expression level was significantly higher in HCC (98). At present, there is no study that specifically investigates the association between circRNAs and the Notch signaling pathway. However, considering that circRNAs are believed to act as inhibitors of miRNA function by binding to a specific miRNA (88), this may indicate a potential association with the Notch signaling pathway similar to miRNAs (47).

\section{Conclusion}

NcRNAs, including miRNAs, lncRNAs and circRNAs, are the main focus of the present review and have the potential to be used as novel biomarkers for cancer in clinical applications. Thus, they may be used for the early detection of cancer, prognostic prediction and sensitivity assessment of chemotherapy and radiotherapy in the future (99). Emerging data suggests that ncRNAs are closely associated with the Notch signaling pathway, and that they serve functions in a variety of types of tumor. At present, there is a comparatively thorough understanding of the interactions between miRNAs and Notch signaling in the development of gastrointestinal cancers. Nevertheless, the exact mechanism by which the other two types of ncRNA (IncRNAs and circRNAs) interact with Notch signaling in gastrointestinal cancer remains unclear. Further 
studies are required to explore the structure and functional features of these ncRNAs, as well as their effects on malignancies. In therapy, contraposing the oncogenic potential of Notch signaling, Notch inhibitors including $\gamma$-secretase inhibitors (GSIs), are effective in inhibiting Notch signaling (4). GSIs have been demonstrated to prevent cell proliferation, migration and invasion in pancreatic cancer (100). Therefore, the present review hypothesizes that the use of a combination of Notch inhibitors and ncRNA analogues may be a beneficial treatment for gastrointestinal cancers. Nevertheless, further studies examining Notch signaling are required, and the novel ncRNAs associated with Notch signaling remain to be identified, notably circRNAs.

\section{Acknowledgements}

The present study was supported by the National Natural Science Foundation of China (grant no. 81672385), the Zhejiang Provincial Natural Science Foundation of China (grant no. LY15H160057), the Science Research Foundation of National Health and Family Planning commission of China (grant no. WKJ-ZJ-1416) and the Wenzhou Science and Technology Bureau Program (grant no. Y20140667).

\section{References}

1. Yuan X, Wu H, Xu H, Xiong H, Chu Q, Yu S, Wu GS and Wu K Notch signaling: An emerging therapeutic target for cancer treatment. Cancer Lett 369: 20-27, 2015.

2. Guilmeau S: Notch signaling and intestinal cancer. Adv Exp Med Biol 727: 272-288, 2012.

3. Morell CM and Strazzabosco M: Notch signaling and new therapeutic options in liver disease. J Hepatol 60: 885-890, 2014.

4. Brzozowa-Zasada M, Piecuch A, Dittfeld A, Mielańczyk Ł Michalski M, Wyrobiec G, Harabin-Słowińska M, Kurek J and Wojnicz R: Notch signalling pathway as an oncogenic factor involved in cancer development. Contemp Oncol (Pozn) 20: 267-272, 2016.

5. Azemar M, Schmidt M, Arlt F, Kennel P, Brandt B, Papadimitriou A, Groner B and Wels W: Recombinant antibody toxins specific for ErbB2 and EGF receptor inhibit the in vitro growth of human head and neck cancer cells and cause rapid tumor regression in vivo. Int J Cancer 86: 269-275, 2000.

6. Wang KC and Chang HY: Molecular mechanisms of long noncoding RNAs. Mol Cell 43: 904-914, 2011.

7. Khurana E, Fu Y, Chakravarty D, Demichelis F, Rubin MA and Gerstein M: Role of non-coding sequence variants in cancer. Nat Rev Genet 17: 93-108, 2016.

8. Hayes EL and Lewis-Wambi JS: Mechanisms of endocrine resistance in breast cancer: An overview of the proposed roles of noncoding RNA. Breast Cancer Res 17: 40, 2015.

9. Bu P, Chen KY, Chen JH, Wang L, Walters J, Shin YJ, Goerger JP, Sun J, Witherspoon M, Rakhilin N, et al: A microRNA miR-34a-regulated bimodal switch targets Notch in colon cancer stem cells. Cell Stem Cell 12: 602-615, 2013.

10. Wang Z, Li Y, Kong D, Ahmad A, Banerjee S and Sarkar FH: Cross-talk between miRNA and Notch signaling pathways in tumor development and progression. Cancer Lett 292: 141-148, 2010.

11. Wang Y, Wu P, Lin R, Rong L, Xue Y and Fang Y: LncRNA NALT interaction with NOTCH1 promoted cell proliferation in pediatric T cell acute lymphoblastic leukemia. Sci Rep 5: 13749, 2015.

12. Katsushima K, Natsume A, Ohka F, Shinjo K, Hatanaka A, Ichimura N, Sato S, Takahashi S, Kimura H, Totoki Y, et al: Targeting the Notch-regulated non-coding RNA TUG1 for glioma treatment. Nat Commun 7: 13616, 2016.

13. Mo YY, Tang H and Miele L: Notch-associated microRNAs in cancer. Curr Drug Targets 14: 1157-1166, 2013.

14. Kopan R and Ilagan MX: The canonical Notch signaling pathway: Unfolding the activation mechanism. Cell 137: 216-233, 2009.

15. Miele L: Notch signaling. Clin Cancer Res 12: 1074-1079, 2006.
16. Mizutani T, Taniguchi Y, Aoki T, Hashimoto N and Honjo T: Conservation of the biochemical mechanisms of signal transduction among mammalian Notch family members. Proc Natl Acad Sci USA 98: 9026-9031, 2001.

17. Chitnis A and Balle-Cuif L: The Notch meeting: An odyssey from structure to function. Development 143: 547-553, 2016.

18. Artavanis-Tsakonas S, Rand MD and Lake RJ: Notch signaling: Cell fate control and signal integration in development. Science 284: 770-776, 1999.

19. Pakkiriswami S, Couto A, Nagarajan U and Georgiou M: Glycosylated Notch and Cancer. Front Oncol 6: 37, 2016.

20. Djiane A, Krejci A, Bernard F, Fexova S, Millen K and Bray SJ: Dissecting the mechanisms of Notch induced hyperplasia. EMBO J 32: 60-71, 2013.

21. Halaoui R and McCaffrey L: Rewiring cell polarity signaling in cancer. Oncogene 34: 939-950, 2015.

22. Andersson ER, Sandberg R and Lendahl U: Notch signaling: Simplicity in design, versatility in function. Development 138: 3593-3612, 2011.

23. Dominguez M: Oncogenic programmes and Notch activity: An 'organized crime'? Semin Cell Dev Biol 28: 78-85, 2014.

24. Ranganathan $P$, Weaver KL and Capobianco AJ: Notch signalling in solid tumours: A little bit of everything but not all the time. Nat Rev Cancer 11: 338-351, 2011.

25. Suh DH, Kim TH, Kim JW, Kim SY, Kim HS, Lee TS, Chung HH, Kim YB, Park NH and Song YS: Improvements to the FIGO staging for ovarian cancer: Reconsideration of lymphatic spread and intraoperative tumor rupture. J Gynecol Oncol 24: 352-358, 2013.

26. Leong KG, Niessen K, Kulic I, Raouf A, Eaves C, Pollet I and Karsan A: Jagged1-mediated Notch activation induces epithelial-to-mesenchymal transition through Slug-induced repression of E-cadherin. J Exp Med 204: 2935-2948, 2007.

27. Meng RD, Shelton CC, Li YM, Qin LX, Notterman D, Paty PB and Schwartz GK: gamma-Secretase inhibitors abrogate oxaliplatin-induced activation of the Notch-1 signaling pathway in colon cancer cells resulting in enhanced chemosensitivity. Cancer Res 69: 573-582, 2009.

28. Wang Z, Li Y, Kong D, Banerjee S, Ahmad A, Azmi AS, Ali S, Abbruzzese JL, Gallick GE and Sarkar FH: Acquisition of epithelial-mesenchymal transition phenotype of gemcitabineresistant pancreatic cancer cells is linked with activation of the notch signaling pathway. Cancer Res 69: 2400-2407, 2009.

29. Garzon R, Calin GA and Croce CM: MicroRNAs in Cancer. Annu Rev Med 60: 167-179, 2009.

30. Umemura $\mathrm{T}$ and Kuroki $\mathrm{C}$ : Circulating MicroRNAs as biomarkers of colorectal cancer. Rinsho Byori 63: 336-346, 2015 (In Japanese).

31. Torre LA, Bray F, Siegel RL, Ferlay J, Lortet-Tieulent J and Jemal A: Global cancer statistics, 2012. CA Cancer J Clin 65: 87-108, 2015.

32. Song Y, Li L, Ou Y, Gao Z, Li E, Li X, Zhang W, Wang J, Xu L, Zhou Y, et al: Identification of genomic alterations in oesophageal squamous cell cancer. Nature 509: 91-95, 2014.

33. Nouraee N, Khazaei S, Vasei M, Razavipour SF, Sadeghizadeh M and Mowla SJ: MicroRNAs contribution in tumor microenvironment of esophageal cancer. Cancer Biomark 16: 367-376, 2016.

34. Liu C, Duan P, Li B, Huang C, Jing Y and Yan W: miR-29a activates Hes1 by targeting Nfia in esophageal carcinoma cell line TE-1. Oncol Lett 9: 96-102, 2015.

35. Ohashi S, Natsuizaka M, Naganuma S, Kagawa S, Kimura S, Itoh H, Kalman RA, Nakagawa M, Darling DS, Basu D, et al: A NOTCH3-mediated squamous cell differentiation program limits expansion of EMT-competent cells that express the ZEB transcription factors. Cancer Res 71: 6836-6847, 2011.

36. Piazzi G, Fini L, Selgrad M, Garcia M, Daoud Y, Wex T, Malfertheiner P, Gasbarrini A, Romano M, Meyer RL, et al: Epigenetic regulation of delta-likel controls Notch1 activation in gastric cancer. Oncotarget 2: 1291-1301, 2011.

37. Yang $G$, Gong $Y$, Wang $Q$, Wang $Y$ and Zhang $X$ : The role of miR-100-mediated Notch pathway in apoptosis of gastric tumor cells. Cell Signal 27: 1087-1101, 2015.

38. Ji Q, Hao X, Meng Y, Zhang M, Desano J, Fan D and Xu L: Restoration of tumor suppressor miR-34 inhibits human p53-mutant gastric cancer tumorspheres. BMC Cancer 8: 266, 2008.

39. Brzozowa M, Mielańczyk L, Michalski M, Malinowski L, Kowalczyk-Ziomek G, Helewski K, Harabin-Słowińska M and Wojnicz R: Role of Notch signaling pathway in gastric cancer pathogenesis. Contemp Oncol (Pozn) 17: 1-5, 2013. 
40. Jiang L, Lin T, Xu C, Hu S, Pan Y and Jin R: miR-124 interacts with the Notch1 signalling pathway and has therapeutic potential against gastric cancer. J Cell Mol Med 20: 313-322, 2016.

41. Li H, Xie S, Liu M, Chen Z, Liu X, Wang L, Li D and Zhou Y: The clinical significance of downregulation of mir-124-3p mir-146a-5p, mir-155-5p and mir-335-5p in gastric cancer tumorigenesis. Int J Oncol 45: 197-208, 2014.

42. Hashimoto Y, Akiyama Y, Otsubo T, Shimada S and Yuasa Y: Involvement of epigenetically silenced microRNA-181c in gastric carcinogenesis. Carcinogenesis 31: 777-784, 2010.

43. Yan C, Yu J, Kang W, Liu Y, MaZ and Zhou L: miR-935 suppresses gastric signet ring cell carcinoma tumorigenesis by targeting Notch1 expression. Biochem Biophys Res Commun 470: 68-74, 2016.

44. Lee YS and Dutta A: MicroRNAs in cancer. Annu Rev Pathol 4: 199-227, 2009.

45. Weng MT, Tsao PN, Lin HL, Tung CC, Change MC, Chang YT, Wong JM and Wei SC: Hes1 increases the invasion ability of colorectal cancer cells via the STAT3-MMP14 pathway. PLoS One 10: e0144322, 2015.

46. Furukawa S, Kawasaki Y, Miyamoto M, Hiyoshi M, Kitayama J and Akiyama T: The miR-1-NOTCH3-Asef pathway is important for colorectal tumor cell migration. PLoS One 8: e80609, 2013

47. Xiong Y, Zhang YY, Wu YY, Wang XD, Wan LH, Li L and Zhou LM: Correlation of over-expressions of miR-21 and Notch-1 in human colorectal cancer with clinical stages. Life Sci 106: 19-24, 2014.

48. Roy S, Levi E, Majumdar AP and Sarkar FH: Expression of miR-34 is lost in colon cancer which can be re-expressed by a novel agent CDF. J Hematol Oncol 5: 58, 2012.

49. Bae Y, Yang T, Zeng HC, Campeau PM, Chen Y, Bertin T, Dawson BC, Munivez E, Tao J and Lee BH: miRNA-34c regulates Notch signaling during bone development. Hum Mol Genet 21 2991-3000, 2012

50. Iwaya T, YokoboriT,Nishida N,Kogo R,SudoT,TanakaF,Shibata K, Sawada G, Takahashi Y, Ishibashi M, et al: Downregulation of miR-144 is associated with colorectal cancer progression via activation of mTOR signaling pathway. Carcinogenesis 33: 2391-2397, 2012.

51. Sureban SM, May R, Mondalek FG, Qu D, Ponnurangam S, Pantazis P, Anant S, Ramanujam RP and Houchen CW: Nanoparticle-based delivery of siDCAMKL-1 increases microRNA-144 and inhibits colorectal cancer tumor growth via a Notch-1 dependent mechanism. J Nanobiotechnology 9: 40, 2011

52. Vickers MM,Bar J, Gorn-Hondermann I, Yarom N, Daneshmand M, Hanson JE, Addison CL, Asmis TR, Jonker DJ, Maroun J, et al: Stage-dependent differential expression of microRNAs in colorectal cancer: Potential role as markers of metastatic disease. Clin Exp Metastasis 29: 123-132, 2012

53. Zhang L, Liu X, Jin H, Guo X, Xia L, Chen Z, Bai M, Liu J, Shang X, Wu K, et al: miR-206 inhibits gastric cancer proliferation in part by repressing cyclinD2. Cancer Lett 332: 94-101, 2013.

54. Song G, Zhang Y and Wang L: MicroRNA-206 targets notch3, activates apoptosis, and inhibits tumor cell migration and focus formation. J Biol Chem 284: 31921-31927, 2009.

55. Gagan J, Dey BK, Layer R, Yan Z and Dutta A: Notch3 and Mef2c proteins are mutually antagonistic via Mkp1 protein and miR-1/206 microRNAs in differentiating myoblasts. J Biol Chem 287: 40360-40370, 2012.

56. Wang XW, Xi XQ, Wu J, Wan YY, Hui HX and Cao XF: MicroRNA-206 attenuates tumor proliferation and migration involving the downregulation of NOTCH3 in colorectal cancer. Oncol Rep 33: 1402-1410, 2015.

57. Maemura K, Natsugoe S and Takao S: Molecular mechanism of cholangiocarcinoma carcinogenesis. J Hepatobiliary Pancreat Sci 21: 754-760, 2014

58. Jung KH,Zhang J,Zhou C, Shen H,Gagea M, Rodriguez-AguayoC, Lopez-Berestein G, Sood AK and Beretta L: Differentiation therapy for hepatocellular carcinoma: Multifaceted effects of miR-148a on tumor growth and phenotype and liver fibrosis. Hepatology 63: 864-879, 2016.

59. Liu M, Lee DF, Chen CT, Yen CJ, Li LY, Lee HJ, Chang CJ, Chang WC, Hsu JM, Kuo HP, et al: IKK $\alpha$ activation of NOTCH links tumorigenesis via FOXA2 suppression. Mol Cell 45: $171-184,2012$

60. Westhoff B, Colaluca IN, D'Ario G, Donzelli M, Tosoni D, Volorio S, Pelosi G, Spaggiari L, Mazzarol G, Viale G, et al: Alterations of the Notch pathway in lung cancer. Proc Natl Acad Sci USA 106: 22293-22298, 2009.
61. Karaczyn A, Bani-Yaghoub M, Tremblay R, Kubu C, Cowling R, Adams TL, Prudovsky I, Spicer D, Friesel R, Vary C and Verdi JM: Two novel human NUMB isoforms provide a potential link between development and cancer. Neural Dev 5: 31, 2010.

62. Gramantieri L, Giovannini C, Lanzi A, Chieco P, Ravaioli M, Venturi A, Grazi GL and Bolondi L: Aberrant Notch3 and Notch4 expression in human hepatocellular carcinoma. Liver Int 27: 997-1007, 2007.

63. Liu W, Xu C, Wan H, Liu C, Wen C, Lu H and Wan F: MicroRNA-206 overexpression promotes apoptosis, induces cell cycle arrest and inhibits the migration of human hepatocellular carcinoma HepG2 cells. Int J Mol Med 34: 420-428, 2014

64. Giovannini C, Gramantieri L, Minguzzi M, Fornari F, Chieco P, Grazi GL and Bolondi L: CDKN1C/P57 is regulated by the Notch target gene Hes1 and induces senescence in human hepatocellular carcinoma. Am J Pathol 181: 413-422, 2012

65. Giovannini C, Minguzzi M, Baglioni M, Fornari F, Giannone F, Ravaioli M, Cescon M, Chieco P, Bolondi L and Gramantieri L: Suppression of p53 by Notch3 is mediated by cyclin G1 and sustained by MDM2 and miR-221 axis in hepatocellular carcinoma. Oncotarget 5: 10607-10620, 2014.

66. Fornari F, Milazzo M, Galassi M, Callegari E, Veronese A, Miyaaki H, Sabbioni S, Mantovani V, Marasco E, Chieco P, et al: p53/mdm2 feedback loop sustains miR-221 expression and dictates the response to anticancer treatments in hepatocellular carcinoma. Mol Cancer Res 12: 203-216, 2014.

67. Jemal A, Bray F, Center MM, Ferlay J, Ward E and Forman D Global cancer statistics. CA Cancer J Clin 61: 69-90, 2011.

68. BaoB, Wang Z,Ali S, Kong D,Li Y,Ahmad A,Banerjee S,Azmi AS, Miele L and Sarkar FH: Notch-1 induces epithelial-mesenchymal transition consistent with cancer stem cell phenotype in pancreatic cancer cells. Cancer Lett 307: 26-36, 2011

69. Arslan AA, Helzlsouer KJ, Kooperberg C, Shu XO, Steplowski E, Bueno-de-Mesquita HB, Fuchs CS, Gross MD, Jacobs EJ, Lacroix AZ, et al: Anthropometric measures, body mass index, and pancreatic cancer: A pooled analysis from the Pancreatic Cancer Cohort Consortium (PanScan). Arch Intern Med 170: 791-802, 2010

70. Plentz R, Park JS, Rhim AD, Abravanel D, Hezel AF, Sharma SV, Gurumurthy S, Deshpande V, Kenific C, Settleman J, et al: Inhibition of gamma-secretase activity inhibits tumor progression in a mouse model of pancreatic ductal adenocarcinoma. Gastroenterology 136: 1741-1749.e6, 2009.

71. Avila JL and Kissil JL: Notch signaling in pancreatic cancer: Oncogene or tumor suppressor? Trends Mol Med 19: 320-327, 2013.

72. Ji Q, Hao X, Zhang M, Tang W, Yang M, Li L, Xiang D, Desano JT, Bommer GT, Fan D, et al: MicroRNA miR-34 inhibits human pancreatic cancer tumor-initiating cells. PLoS One 4: e6816, 2009.

73. Cifarelli V, Lashinger LM, Devlin KL, Dunlap SM, Huang J, Kaaks R, Pollak MN and Hursting SD: Metformin and rapamycin reduce pancreatic cancer growth in obese prediabetic mice by distinct microRNA-regulated mechanisms. Diabetes 64: 1632-1642, 2015.

74. Sureban SM, May R, Lightfoot SA, Hoskins AB, Lerner M, Brackett DJ, Postier RG, Ramanujam R, Mohammed A, Rao CV, et al: DCAMKL-1 regulates epithelial-mesenchymal transition in human pancreatic cells through a miR-200adependent mechanism. Cancer Res 71: 2328-2338, 2011.

75. Wang Z, Banerjee S, Ahmad A, Li Y, Azmi AS, Gunn JR, Kong D, Bao B, Ali S, Gao J, et al: Activated K-ras and INK4a/Arf deficiency cooperate during the development of pancreatic cancer by activation of Notch and NF- $\mathrm{kB}$ signaling pathways. PLoS One 6: e20537, 2011

76. Brabletz S, Bajdak K, Meidhof S, Burk U, Niedermann G, Firat E, Wellner U, Dimmler A, Faller G, Schubert J and Brabletz T: The ZEB1/miR-200 feedback loop controls Notch signalling in cancer cells. EMBO J 30: 770-782, 2011.

77. Ma J, Cheng L, Liu H, Zhang J, Shi Y, Zeng F, Miele L, Sarkar FH, Xia J and Wang Z: Genistein down-regulates miR-223 expression in pancreatic cancer cells. Curr Drug Targets 14: 1150-1156, 2013.

78. Ma J, Fang B, Zeng F, Ma C, Pang H, Cheng L, Shi Y, Wang H, Yin B, Xia J and Wang Z: Down-regulation of miR-223 reverses epithelial-mesenchymal transition in gemcitabine-resistant pancreatic cancer cells. Oncotarget 6: 1740-1749, 2015.

79. Prueitt RL, Yi M, Hudson RS, Wallace TA, Howe TM, Yfantis HG, Lee DH, Stephens RM, Liu CG, Calin GA, et al: Expression of microRNAs and protein-coding genes associated with perineural invasion in prostate cancer. Prostate 68: 1152-1164, 2008. 
80. Mees ST, Mardin WA, Sielker S, Willscher E, Senninger N, Schleicher C, Colombo-Benkmann $\mathrm{M}$ and Haier J: Involvement of CD40 targeting miR-224 and miR-486 on the progression of pancreatic ductal adenocarcinomas. Ann Surg Oncol 16: 2339-2350, 2009.

81. Zhang B, Guo X,Zhang J,Liu X,Zhan X and Li Z: MicroRNA224 is downregulated in mucinous cystic neoplasms of the pancreas and may regulate tumorigenesis by targeting Jagged1. Mol Med Rep 10: 3303-3309, 2014.

82. Maniati E, Bossard M, Cook N, Candido JB, Emami-Shahri N, Nedospasov SA, Balkwill FR, Tuveson DA and Hagemann T: Crosstalk between the canonical NF- $\mathrm{KB}$ and Notch signaling pathways inhibits Ppar $\gamma$ expression and promotes pancreatic cancer progression in mice. J Clin Invest 121: 4685-4699, 2011.

83. Li CH and Chen Y: Targeting long non-coding RNAs in cancers: Progress and prospects. Int J Biochem Cell Biol 45: 1895-1910, 2013.

84. Audas TE and Lee S: Stressing out over long noncoding RNA. Biochim Biophys Acta 1859: 184-191, 2016.

85. Hang Q, Sun R, Jiang C and Li Y: Notch 1 promotes cisplatin-resistant gastric cancer formation by upregulating lncRNA AK022798 expression. Anticancer Drugs 26: 632-640, 2015.

86. He Y, Meng XM, Huang C, Wu BM, Zhang L, Lv XW and Li J: Long noncoding RNAs: Novel insights into hepatocelluar carcinoma. Cancer Lett 344: 20-27, 2014

87. Tang J, Zhuo H, Zhang X, Jiang R, Ji J, Deng L, Qian X, Zhang F and Sun B: A novel biomarker Linc00974 interacting with KRT19 promotes proliferation and metastasis in hepatocellular carcinoma. Cell Death Dis 5: e1549, 2014

88. Ebbesen KK, Kjems J and Hansen TB: Circular RNAs: Identification, biogenesis and function. Biochim Biophys Acta 1859: 163-168, 2016

89. Memczak S, Jens M, Elefsinioti A, Torti F, Krueger J, Rybak A, Maier L, Mackowiak SD, Gregersen LH, Munschauer M, et al Circular RNAs are a large class of animal RNAs with regulatory potency. Nature 495: 333-338, 2013.

90. Li J, Yang J, Zhou P, Le Y, Zhou C, Wang S, Xu D, Lin HK and Gong Z: Circular RNAs in cancer: Novel insights into origins, properties, functions and implications. Am J Cancer Res 5: $472-480,2015$

91. Hansen TB, Jensen TI, Clausen BH, Bramsen JB, Finsen B, Damgaard CK and Kjems J: Natural RNA circles function as efficient microRNA sponges. Nature 495: 384-388, 2013.

92. Zhao ZJ and Shen J: Circular RNA participates in the carcinogenesis and the malignant behavior of cancer. RNA Biol 14 514-521, 2017.
93. Zheng Q, Bao C, Guo W, Li S, Chen J, Chen B, Luo Y, Lyu D, $\mathrm{Li} \mathrm{Y}$, Shi G, et al: Circular RNA profiling reveals an abundant circHIPK3 that regulates cell growth by sponging multiple miRNAs. Nat Commun 7: 11215, 2016.

94. Xie H, Ren X, Xin S, Lan X, Lu G, Lin Y, Yang S, Zeng Z, Liao W, Ding YQ and Liang L: Emerging roles of circRNA_001569 targeting miR-145 in the proliferation and invasion of colorectal cancer. Oncotarget 7: 26680-26691, 2016.

95. Li P, Chen S, Chen H, Mo X, Li T, Shao Y, Xiao B and Guo J: Using circular RNA as a novel type of biomarker in the screening of gastric cancer. Clin Chim Acta 444: 132-136, 2015.

96. Wang X, Zhang Y, Huang L, Zhang J, Pan F, Li B, Yan Y, Jia B, Liu H, Li S and Zheng W: Decreased expression of hsa circ_001988 in colorectal cancer and its clinical significances. Int J Clin Exp Pathol 8: 16020-16025, 2015.

97. Qin M, Liu G, Huo X, Tao X, Sun X, GeZ, Yang J, Fan J, Liu L and Qin W: Hsa_circ_0001649: A circular RNA and potential novel biomarker for hepatocellular carcinoma. Cancer Biomark 16: 161-169, 2016

98. Shang X, Li G, Liu H, Li T, Liu J, Zhao Q and Wang C: Comprehensive circular RNA profiling reveals that hsa circ_0005075, a new circular RNA Biomarker, is involved in hepatocellular crcinoma development. Medicine (Baltimore) 95 e3811, 2016

99. Yamamoto H, Toyooka S, Maki Y, Soh J and Miyoshi S Significance of noncoding RNA in surgery: Noncoding RNA in lung cancer. Nihon Geka Gakkai Zasshi 116: 374-377, 2015 (In Japanese).

100. Palagani V, Bozko P, El Khatib M, Belahmer H, Giese N, Sipos B, Malek NP and Plentz RR: Combined inhibition of Notch and JAK/STAT is superior to monotherapies and impairs pancreatic cancer progression. Carcinogenesis 35: 859-866, 2014.

101. Pei J and Wang B: Notch-1 promotes breast cancer cells proliferation by regulating LncRNA GAS5. Int J Clin Exp Med 8: 14464-14471, 2015

102. Trimarchi T, Bilal E, Ntziachristos P, Fabbri G, Dalla-Favera R, Tsirigos A and Aifantis I: Genome-wide mapping and characterization of Notch-regulated long noncoding RNAs in acute leukemia. Cell 158: 593-606, 2014.

103. Li F, Zhang L, Li W, Deng J, Zheng J, An M, Lu J and Zhou Y: Circular RNA ITCH has inhibitory effect on ESCC by suppressing the Wnt/ $\beta$-catenin pathway. Oncotarget 6 : 6001-6013, 2015. 